\title{
栚 Bench mining utilizing manual labour and mechanized equipment - a proposed mining method for artisanal small-scale mining in Central Africa
}

\author{
by S.M. Rupprecht*
}

\section{Synopsis}

Artisanal mining is basic mining characterized by manually intensive work methods utilizing primitive or simple equipment and conducted by individuals or small groups exploiting deposits. Artisanal mining in Rwanda and Burundi is further complicated in that the techniques applied are often inadequate, resulting in low productivity and poor recoveries, and workers are paid low wages with owners reluctant to reinvest in the mining operations. A consequence of this vicious circle is often poor working conditions, with miners operating under unsafe and/or unhealthy working conditions. An additional problem is that mining is conducted in a manner that is detrimental to the environment.

Artisanal mining is commonly more dangerous than large-scale modern mining operations. Artisanal operations are generally subsistence activities with the miners focusing more on immediate concerns than the long-term consequences of their activities. When miners have no other source of income, they will usually find ways to evade controls and carry on working. Machinery tends to be expensive and often far beyond the reach of most artisanal miners, and therefore there is a general tendency for workers to focus on labour intensive and riskier mining methods.

This paper proposes the introduction of small-scale mechanization with labour-intensive manual mining utilizing a bench mining approach in artisanal mines operating in Central Africa. From the 1950s to the 1980s bench mining was successfully conducted in Burundi utilizing manual labour. In order to achieve a balance between job creation and project economics, the combination of manual and mechanized mining is proposed. Manual mining offers the benefit of local job creation while ensuring good mining techniques, such as minimizing mining loses and dilution. Through the introduction of mechanized loading and hauling activities, areas of high stripping ratios can be viably mined, thus increasing the amount of resources that can be exploited. The use of a loader and tractor-trailer arrangement is proposed, thereby improving throughput, productivity, and worker safety and, reducing the impact on the environment.

Keywords

artisanal mining, small-scale mining, bench mining, mechanization.

\section{Introduction}

Surface mining is generally the easiest form of mining for artisanal small-scale miners, as the mineral of interest is either outcropping or is very close to surface, requiring less effort to access and, to a certain extent, entailing a reduced risk to mineworkers. In principle, the lower the stripping ratio (waste to ore ratio) the greater the profits. Bench mining offers a simple and safe method to exploit a deposit, but requires a systematic approach, with the removal of waste and ore in a sequence.
Figure 1 demonstrates the open pit mining method applying a sequential approach to mining.

The current practice in most Rwandan and Burundian mines is to mine waste and mineralized material simultaneously, transporting the material into a single gully and making use of gravity and water to assist with the mining of the deposit. However, this is often a risky practice as the overburden is often weak and can easily collapse (Figure 2), especially when wet (Rupprecht, 2012).

Bench mining is not an unknown method in Central Africa, and was applied in the mid20th century, as seen in Figure 3. The purpose of this paper is to describe a viable bench mining method that employs both manual mining and mobile machinery, thereby offering employment to the local community while constituting a safe and a productive mining method.

Before discussing the transformation of artisanal mining to small-scale mining, an understanding of the two terms is required, as they can mean different things to different people.

\section{Artisanal mining}

The World Bank defines artisanal mining as 'a type of manual, low technology mining conducted on a small scale, predominantly in rural areas of the developing world'. Artisanal mining is the smallest and simplest mining operations, which involves the use of simple tools with basic mining and processing techniques. Because of the informal nature of these operation, even subsistence farmers may get involved in mining on a seasonal basis.

* University of Johannesburg, South Africa.

(c) The Southern African Institute of Mining and Metallurgy, 2017. ISSN 2225-6253. This paper was first presented at the Mining, Environment and Society Conference 'Beyond sustainabilityBuilding resilience', 12-13 May 2015, Mintek, Randburg, South Africa. 


\section{Bench mining utilizing manual labour and mechanized equipment}

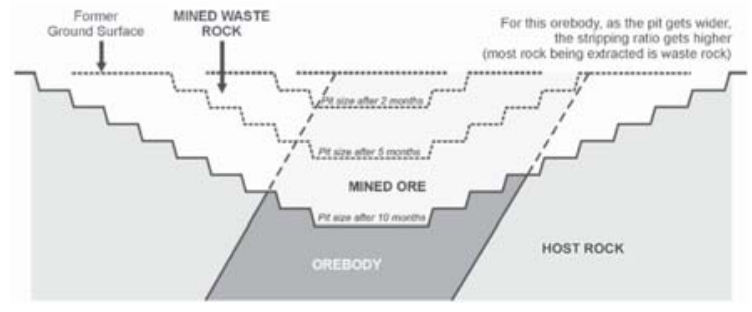

Figure 1-Open pit mining (Hinton, n.d.)

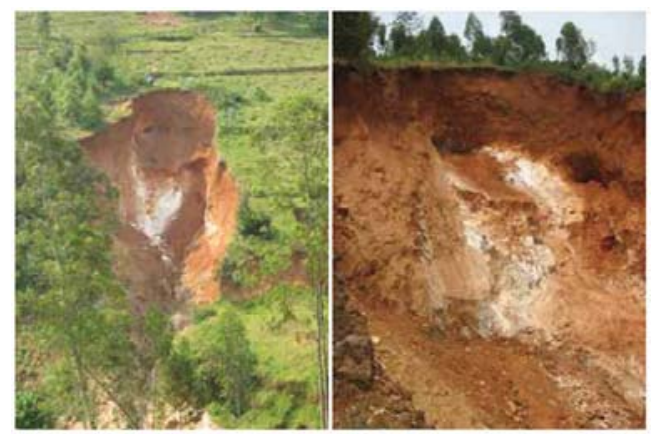

Figure 2-Highwall failure at a surface mining operation in Central Africa

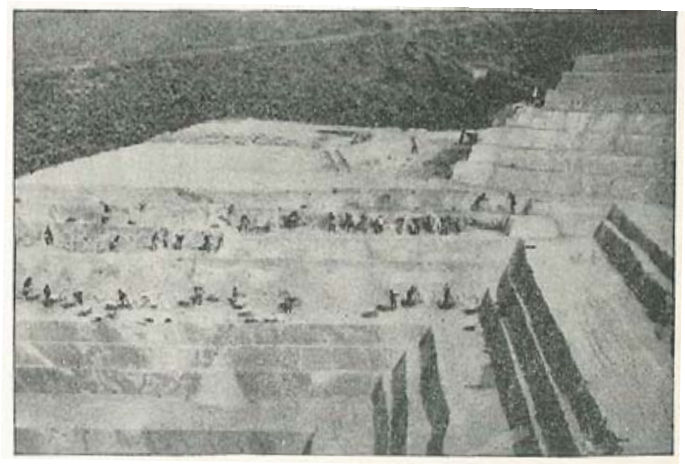

Figure 3-Bench mining as conducted in Burundi in 1957 (Thoreau, 1958)

\section{Small-scale mining}

Small-scale mining involves the use of basic mining and processing technology such as mechanical drilling and blasting, mechanized loading and hauling, hoisting, and processing by gravity concentration and similar techniques. Traditional small-scale mining includes licensed and registered non-mechanized or semi-mechanized mining operations, usually run by individual or organized cooperatives. Small-scale mining usually utilizes hired or contract labour and applies basic management principles in the operations.

\section{The general nature of artisanal mining in Central Africa}

The artisanal mining sector in Central Africa is largely informal, yet provides an essential livelihood for many participants (directly or indirectly), as well as providing an important source of income for many communities. According to Biryabarema (2014), the ratio of jobs created to support artisanal mining is 5 to 1 Artisanal mining varies from site to site, but appears largely well structured despite its informality. The artisanal mining sites have some inherent management structure and the extraction itself is often organized through teams of about 10 to 20 diggers in a working area; these are generally accompanied by supporting crews (e.g. transporters, rock crushers, mineral washers, and waste disposal crews). Payment is usually based on the mineral content of the concentrate produced.

The hazards for artisanal surface mining include highwall collapse or slumping, falling from heights, rockfalls from slopes above the workings, and undermining of pit highwalls. Mining is labour-intensive and is generally conducted utilizing hand digging methods, e.g. shovels or hammer and chisels. Artisanal mining is generally more dangerous than large-scale modern mining operations, as artisanal operations are generally subsistence activities with the miners focusing more on immediate concerns than the long-term consequences of their activities. When miners have no other source of income, they will usually find ways to evade controls and carry on working.

A wide range of skills and abilities is used to exploit the varied deposits, but in general there is a low level of understanding of safety and compliance with governmental rules, standards, or regulations. The objective of the government agencies, non-government organizations (NGOs), owners, and other concerned parties operating in Rwanda and Burundi is to find a safe and realistic approach to improve mining conditions, raise safety, health, and environment awareness, and improve the overall productivity of the operations in a manner appropriate to local circumstances while maintaining employment levels. The capacity of government to oversee the artisanal mining sector is limited and is currently ineffective due to the government's inability to cover the vast areas under their responsibility, the high number of granted concessions, budgetary and logistical constraints, and shortage of personnel and technical knowledge.

Any remedial action proposed should be transparent to the artisanal mining community and should be presented to all stakeholders with real local ownership. The formalization initiatives must secure local buy-in in order to succeed and achieve results in the long term.

\section{Safety, health, and environmental issues}

There appears to be a difficulty in providing clear mine safety, health, and environment standards for mining operations. Occupational safety, health, and environmental guidelines, which are usually unenforceable, are often set as mandatory codes of practice for mines and quarries. These guidelines discuss safety, health, and environmental issues in general and are suitable for formal small-scale mining operations rather than informal operations, and are therefore, for the most part, irrelevant to artisanal mining operations. Attempting to apply standard codes of practices to artisanal mining may be detrimental, as unrealistic standards or expectations could be imposed on the mines and workers. Rather, the focus should be on the development of basic mining skills to improve current mining practices. 


\section{Bench mining utilizing manual labour and mechanized equipment}

The implementation of mining standards at artisanal mining operations must be viewed in context. Artisanal mining is currently mostly subsistence work, and thus safety standards may be seen as interference and could adversely affect workers' income. It is critical that mine owners realize the importance of finding a balance between standards and the need to improve the working conditions. Standards must be relevant, and the introduction of safety measures should be seen as requiring buy-in from a number of stakeholders; starting with the miners themselves and including the mine owners, governmental agencies, the community, and mineral buyers. Appropriate minimum standards should be identified and progressive improvement in standards established. The implementation of mine health and safety standards should be seen as a process with immediate to short-, medium-, and long-term goals. Fundamental to the improvement of mine safety is the introduction of increased productivity.

Artisanal miners must be able to understand the benefits of the proposed safety standards in order to facilitate meaningful change. Initial standards must be realistic and achievable so that immediate results can be seen, thereby encouraging the miners to commit to and remain engaged in the process. Unrealistic goals will result in noncompliance and failure. To some extent mine owners will be required to enforce basic safety standards. Failure to comply should result in corrective action being taken by the government and the threat of losing technical or financial support or the actual mining concession.

Based on over five years of artisanal mining audits, the author concludes that artisanal miners are willing to adopt safety standards and better practices. Rewarding positive behaviour should be considered to jump-start the safety process so as to create a positive response. This could be in the form of an increase in salary or the purchase price of the metal/concentrate linked to general safety compliance and performance. It must be understood by all participants that transformation will incur some costs. The cost of such action needs to be shared between government, owners, workers, and buyers.

\section{Current mining methods}

Mining is often conducted in an up-dip orientation (Figure 4) with water being used to move the mineralized material downwards into gullies or slushers (Figure 5), where it is concentrated. Mining tools consists of picks and shovels. Material is excavated off the face using picks, with workers forming a line and transporting the material with shovels down-dip to the slusher in the centre of the mining area. In

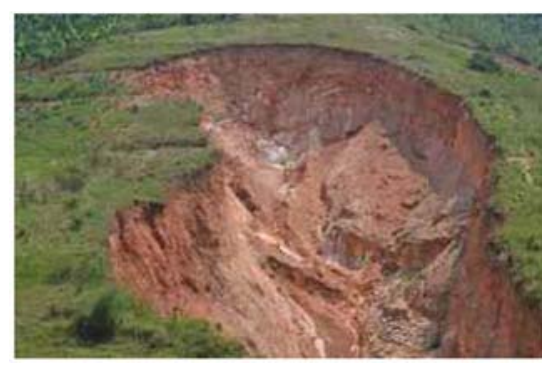

Figure 4-Highwall mining (Rupprecht, 2015a) some cases small tunnels (Figure 6) up to several metres in length are developed into the deposit, which then induces the overburden to collapse; or in other cases water accumulates on the surface where if causes swelling of the soil, resulting in the collapse of the highwall area. In the gully, the heavier material is concentrated and stockpiled adjacent to the gully at the base of mining operations. The remaining material that has not been concentrated continues downstream where it eventually settles, with the heaviest material settling close to the mining operation while the lighter material can travel several hundreds of metres downstream.

\section{Attempt to introduce bench mining in Rwanda}

After a review of several artisanal mining operations near Kigali, Rwanda (Rupprecht 2012), bench mining was introduced at one of the mining sites. The introduction of bench mining was based on a mineworker loading $10 \mathrm{~m}^{3}$ (in situ) of rock in eight hours. Based on a working bench height of $3 \mathrm{~m}, 10$ lifts were required to mine a $30 \mathrm{~m}$ height. This design resulted in a slope length of $70 \mathrm{~m}$ and a deposit width of $9 \mathrm{~m}$ (Figure 7). Bench widths of $4 \mathrm{~m}$ were proposed to establish an overall slope angle of 37 degrees. In order to exploit a $9 \mathrm{~m}$ deep excavation three benches were required, which created a $12 \mathrm{~m}$ wide waste strip on either side of the excavation. Based on a 15-man mining crew, approximately $14000 \mathrm{~m}^{3}$ of material was required to be handled, which

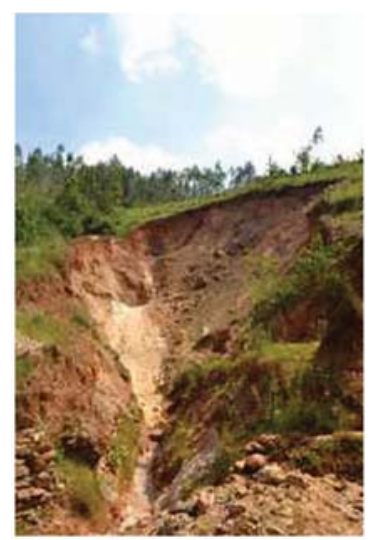

Figure 5-Slusher used in up-dip mining

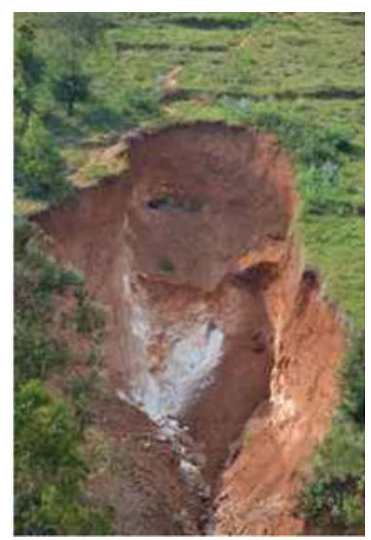

Figure 6-Tunnel into highwall (Rupprecht, 2015b) 


\section{Bench mining utilizing manual labour and mechanized equipment}

equated to three months to mine a $30 \mathrm{~m}$ section. A schematic of the mining sequence is depicted in Figure 8 (Rupprecht, 2012).

The proposed mining plan failed, mainly due to the poor commitment of the owner, who was reluctant to pay for the additional costs. Little effort was made to implement the new mine design and within a number of days the operation returned to normal highwall mining. Even while operations were temporarily stopped so that the new mine design could be implemented, several of the miners entered the work site to conduct illegal mining during the hours of darkness. The lessons learned included the requirement for proper buy-in from all participants, correct supervision to ensure the mine plan is adhered to, and appropriate remuneration related to the additional work associated with bench mining. A fundamental conclusion from this exercise was the need to improve worker productivity so as to provide funding for the additional work. Thus, safety initiatives must be associated with real productivity gains or else the attempt to change will not succeed.

\section{Bench mining method}

The following section describes two approaches to conducting safe bench mining. Figure 9 indicates the start or the first cut of bench mining from the side of a hill or mountain. The proposed height between roads is $4.5 \mathrm{~m}$, with road widths of $6 \mathrm{~m}$. Figure 10 is a schematic of mining with a tractorloader-bucket (TLB) arrangement, which can be used to establish mining operations. Alternatively, the cuts can be developed by hand mining methods as depicted in Figure 7 and Figure 8.

\section{Manual work combined with mechanical loading and hauling}

Based on observations made by the author in Rwanda and Burundi, one man can load $1 \mathrm{~m}^{3}$ to $10 \mathrm{~m}^{3}$ (in situ) of rock in eight hours, depending mainly on the geology, the size and density of the rock pieces, and the height to be lifted.

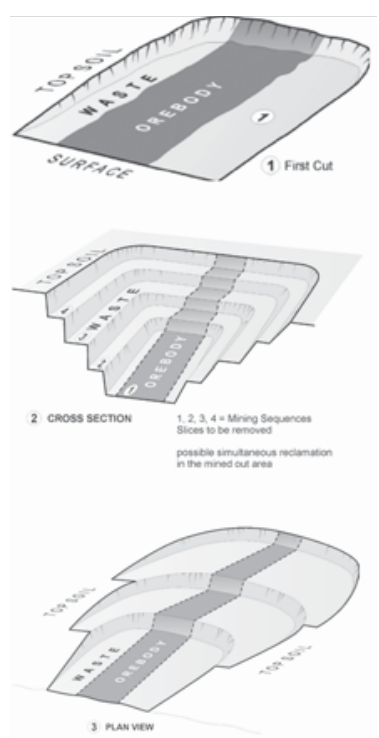

Figure 7-Schematic of bench mining - first cut (Rupprecht, 2012)
The bench configuration is based on empirical design, relying on in-field measurements from a number of defunct Belgian operations that were mined during the 1950s. Some
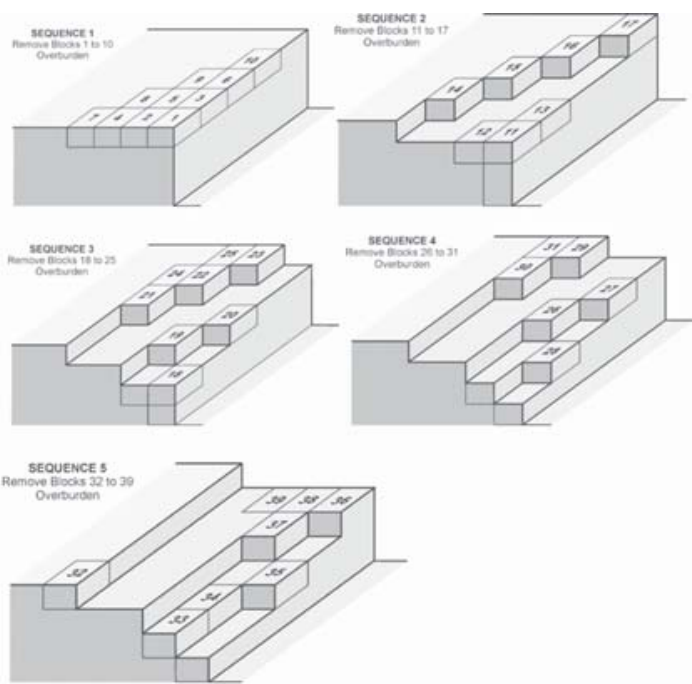

Figure 8-Schematics of bench mining sequences (Rupprecht, 2012)
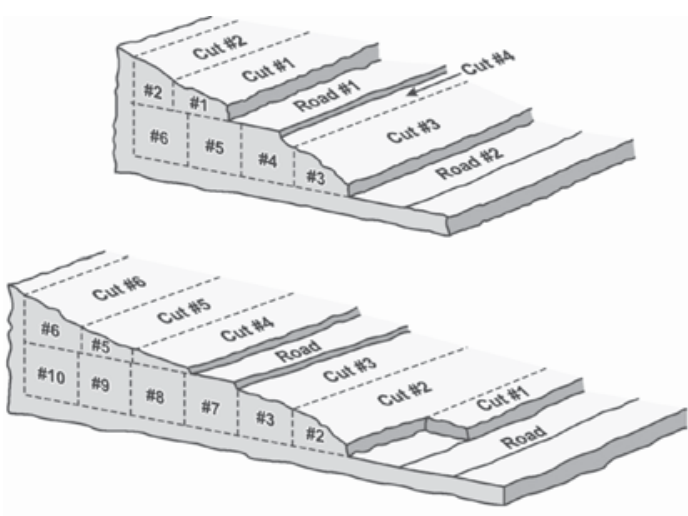

Figure 9-Schematics of bench mining sequences (Nichols, 1956)
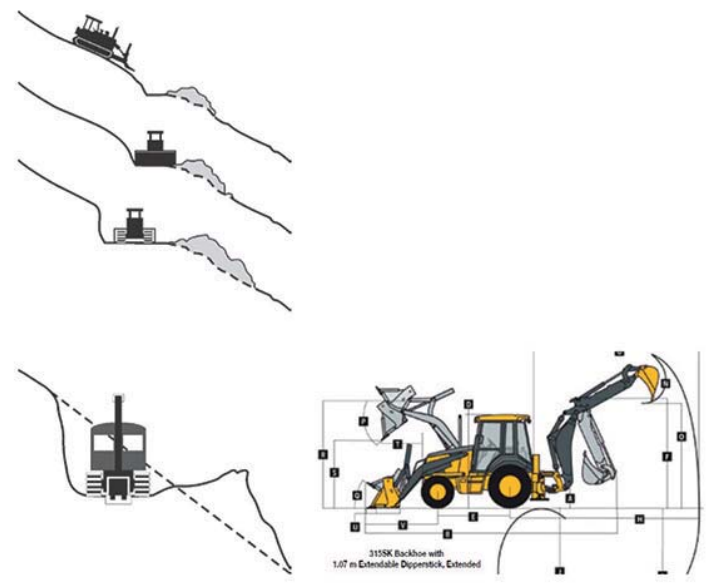

Figure 10-Dozer and TBL establishing bench mining (Nichols, 1956; Bell, 2014) 


\section{Bench mining utilizing manual labour and mechanized equipment}

60 years later the benches and slopes remain in a stable condition. The original bench design was used for the new proposed mine design. Thus, a working mining cut height of $1.5 \mathrm{~m}$ utilizing three lifts is proposed to mine a $4.5 \mathrm{~m}$ bench height. Utilizing a $0.5 \mathrm{~m}$ stepover per mining cut, an overall slope angle of 37 degrees is created.

Mechanized loading can be done with a multi-terrain loader (Figure 11) or a TLB, which can be used to excavate and load the bench material. A typical $3 \mathrm{t}$ machine is $1.75 \mathrm{~m}$ wide and $3.5 \mathrm{~m}$ long, with a reach of $3.8 \mathrm{~m}$ and a tipping height of $2.2 \mathrm{~m}$. Based on a bucket fill factor of $85 \%$ the loader has a rated operating capacity of $2.1 \mathrm{t}$ and is capable of a maximum speed of $11.3 \mathrm{~km} / \mathrm{h}$ with the ability to navigate gradients up to 40 degrees.

The use of mechanical equipment poses a risk to the operator, hence thorough training is required. It is envisaged that the loader would require access roads to the mining benches. Access ramps and benches should be $6 \mathrm{~m}$ wide inclusive of a $1 \mathrm{~m}$ safety berm. The width of the bench is based on the overall body width of the tractor-trailer unit utilizing the standard factor (Thompson, n.d.) of twice the body width ( $2.5 \mathrm{~m}$ width of haulage equipment plus $1 \mathrm{~m}$ berm). Access to the benches will be by ramps designed with a slope of about 10 degrees.

There are many multi-terrain loaders available in the market, with purchase prices in the order of US\$65000 to US\$95 000. A TLB would cost in the range of US\$87000 (Bell, 2016).

\section{Mining cycle}

\section{Drill and blast}

For the majority of artisanal mining operations in Central Africa no drilling and blasting is required due to the weathered nature of the host rock. Fresh rock is usually encountered $20 \mathrm{~m}$ below surface, which is often beyond the economic viability for open pit mining in many low-grade and low value metal deposits such as tin, tungsten, and tantalite.

\section{Load and haul}

Loading of mineralized and waste material will be conducted by a combination of manual shovelling and mechanized loading. Mineralized material will be broken using picks, pinch bars, and shovels and the broken material either handloaded or mucked into trailers utilizing a multi-terrain loader. The broken material will then be transported to the beneficiation plant by a tractor-trailer arrangement, as shown in Figure 12 and Figure 13. Waste material is handled in a similar manner, and transported to the waste dump.

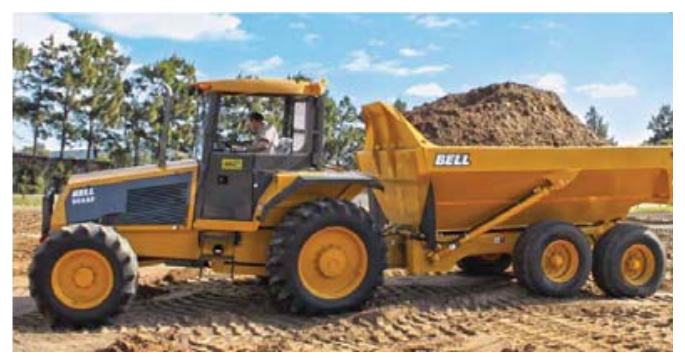

Figure 12-Tractor-trailer arrangement (Bell, 2014)

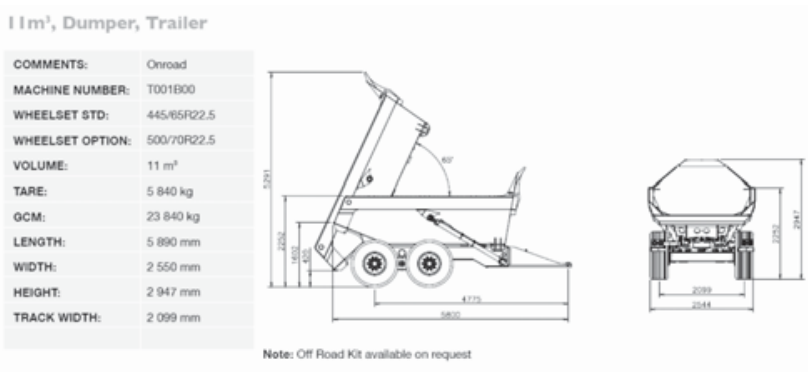

Figure 13-Schematic of dumper-trailer (Bell, 2014)

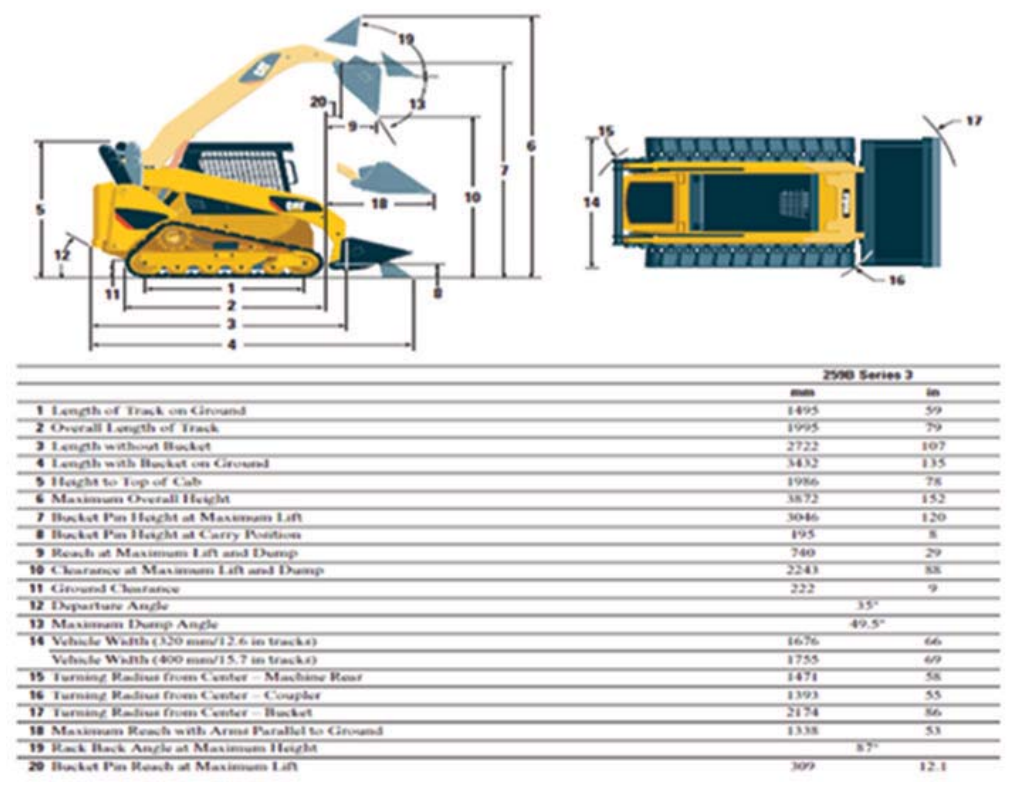




\section{Bench mining utilizing manual labour and mechanized equipment}

\section{Mineral processing}

Mineral process is typically conducted by means of sluicing or panning (Figure 14). Mineral processing in artisanal mining is generally inefficient, with recoveries in the order of $30 \%$. Recovery improvements between $10 \%$ and $30 \%$ can be achieved through the use of modern processing techniques. However, due to the size of the deposits and the entry costs of modern processing techniques, up-to-date processing equipment is usually beyond the reach of artisanal miners.

\section{Waste and tailings disposal}

Waste management is an integral part of the mining cycle. The use of mechanized equipment allows waste to be loaded and hauled to selected and approved sites (Figure 15). These storage facilities can be benched and contoured and used to plant crops such as cassava or coffee. The volume of waste material will depend on the mine design and therefore sufficient areas will be required to be secured for waste storage. The site that is nearest the beneficiation plant is not always the best option for tailings disposal. The cost, safety, and environmental aspects must be investigated for a number of different options. Slope stability is important, and therefore a slope of less than 20 degrees should be considered with a 3:1 slope used as a rule of thumb. It is recommended that a qualified engineer design, construct, and monitor waste and tailing storage facilities. Precautions should be taken to ensure that any failure of the storage facility would not contaminate watercourses. As the host rock usually does not contain any detrimental elements, the main environmental concern is to control sediment deposition in the creeks and streams. Figure 17 illustrates one of the Rwandan operations making use of a designated tailings facility with tailing material contained with a dam area and spillage ditches used to catch run-off sediments.
Figure 16 depicts silting in streams adjacent to artisanal mining sites. Water management is an important aspect of waste and tailings storage, and a plan is required to control the movement and storage of clean and dirty water. Under no circumstance should water be released uncontrolled into the environment. Ditches and drains should be used to control, direct, and collect water.

Currently, based on the author's observations over the past five years, most mines are treating mineralized material and waste together, thus requiring the storage of a significant amount of waste/tailings material. Bench mining improves waste management through the separation of waste and mineralized material before mineral processing, thereby allowing waste material to be properly stored, and significantly reducing the amount of material to be processed and tailings material to be contained.

\section{Conclusions and recommendations}

Many artisanal mining operations are unsafe and do not adhere to good mining practices or meet the minimum

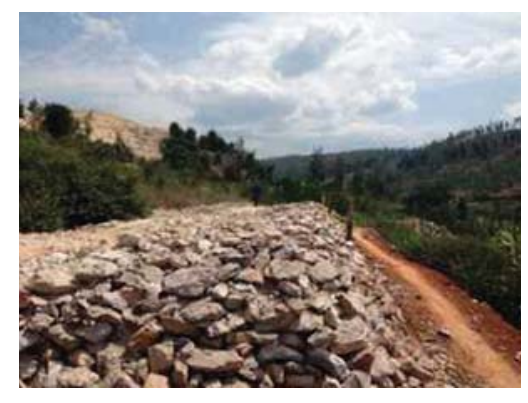

Figure 15-Waste rock dump

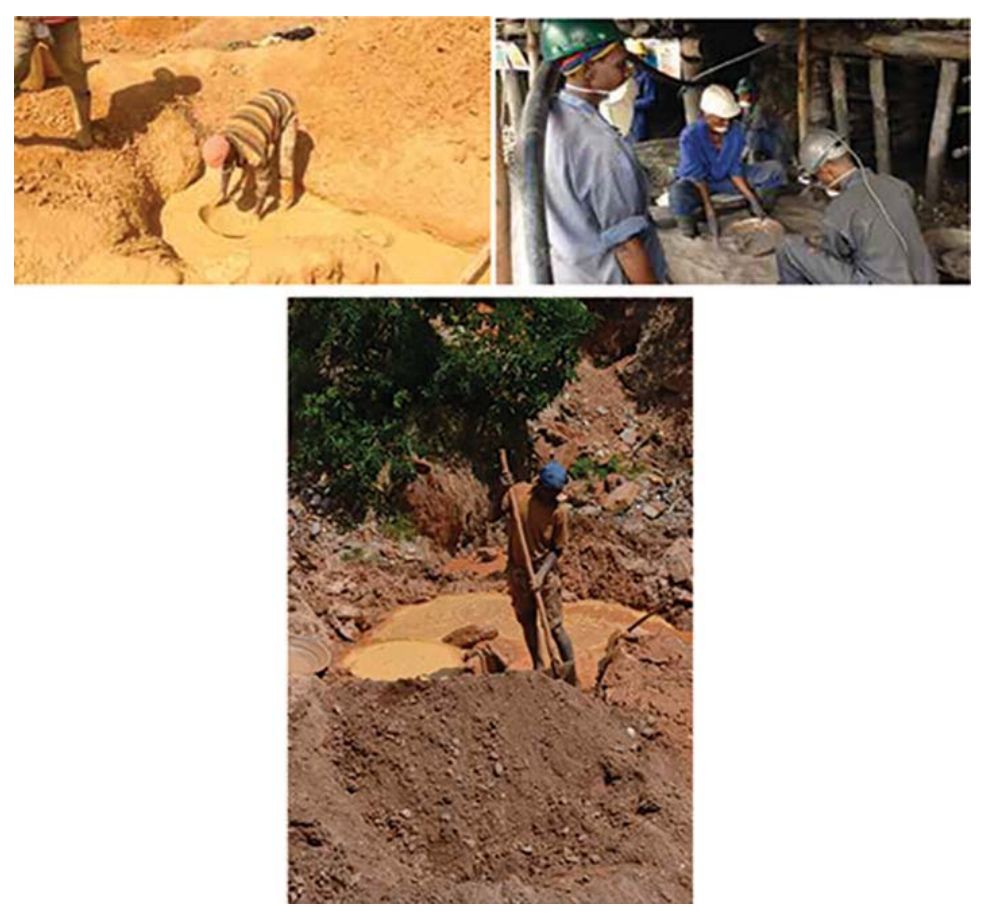

Figure 14-Panning operations 


\section{Bench mining utilizing manual labour and mechanized equipment}
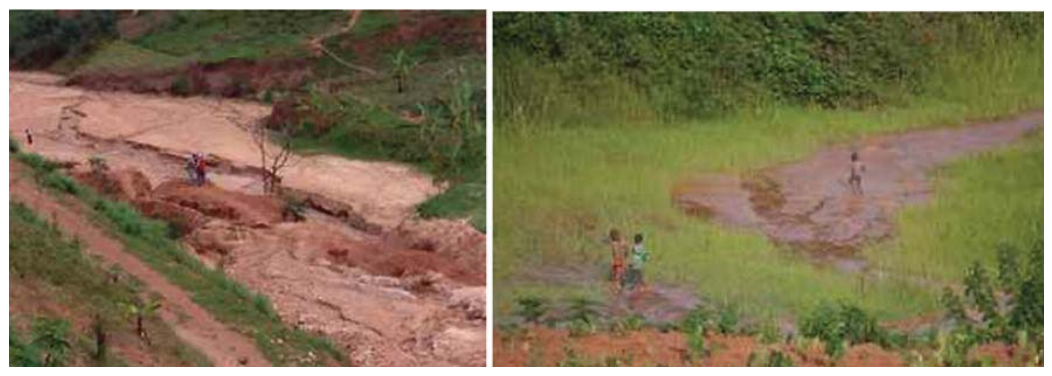

Figure 16-Tailings in streams

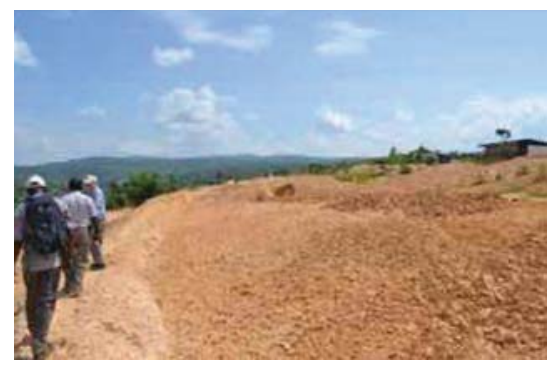

Management and planning of waste handling and storage facilities will be critical to ensure that sufficient mineralized material is excavated timeously to support the proposed production profile. In addition, the mine design should include the waste storage facility that has the least impact on the environment.

\section{References}

Figure 17-Tailings facility site

requirements set out by most government mining departments.

Where appropriate, bench mining can be undertaken to improve highwall conditions, increase slope stability, improve general safety, and increase productivity. Bench mining can be undertaken utilizing picks, shovels, and wheelbarrows, with the potential to increase productivity through the introduction of mechanization. Detail mine designs are required for each project site, as each site will have its own particular geological conditions and mine design requirements.

Manual bench mining should be the surface mining method of choice for remote operations or concessions that have limited mineral resources. Mechanized mining utilizing a dozer or hydraulic shovel is currently applied by some mines, but is applied intermittently, and often does not provide a positive return on the investment of hiring the equipment. The use of small multi-terrain loaders, TLBs, and tractor-trailers with haulage benches is a practical solution for small- to medium-sized deposits with moderate stripping ratios.

Along with the introduction of bench mining, work standards must be put in place to ensure that workers adhere to the basic safety, health, and environmental guidelines. The value-add for mine owners and workers will be through the improvement of productivity and the revenue generated from the increased output. The use of mechanized equipment will require strict supervision and adherence to the mine plan to ensure that machinery operates only on level benches. A fundamental conclusion from this research is the need to improve worker productivity to such an extent that the additional work is adequately funded. Safety initiatives must be associated with real productivity gains or else the attempt to change will not succeed.

Bell EQuipment. Not dated. $11 \mathrm{~m}^{3}$ dumper trailer brochure, Broch/1156/04/12Trailers.

BELL EQUiPMENT SARL. 2016. (RDC) Quotation new Bell backhoe, 15/9/2016. Personnel communication.

Biryabarema, M. 2014. Director, Rwanda Geology and Mines authority, Kigali, Rwanda. Personal communication.

CATERPILLAR. 2014. Skid track loader. http://www.cat.com/en_us/product/new/ equipment/compact-track-and -multiterrain loader/18484359.html

HinTon, J. Not dated. Small scale mining handbook - a guideline for improving the performance of artisanal and small scale mining in Uganda. Training and Awareness Campaign Committee (TACC), Sustainable Management of Mineral Resources Project, Ministry of Energy and Mineral Development Deptartment of Geological Survey and Mines.

Nichols, H.L. JR. 1956. Modern Techniques of Excavation. Van Norstrand, Princeton, NJ.

RUPPRECHT, S.M. 2012. Havila safety and review. Borrego Sun Consultancy, Johannesburg.

RuPPRECHT, S.M. 2015a. Needs analysis for small scale mining. Journal of the Southern African Institute of Mining and Metallurgy, vol. 115. pp. 1007-1012.

RUPPRECHT, S.M. 2015b. Safety aspects and recommendations for surface artisanal mining. Proceedings of Copper Cobalt Africa - The 8th Southern African Base Metals Conference, Victoria Falls, 6-8 July 2015. Southern African Institute of Mining and Metallurgy, Johannesburg. -

Thompson, R.J. Not dated Mine haul road design, construction and maintenance management. http://www.slideshare.net/hungtranviet90281/mine-haulroad-design-construction-and-maintenance-management

Thoreau, J., Aderca, B., and van WAMBeKe, L. (1958): Le Gisement DE terRes rares de Karonge (Urundi). Bulletin des Séances de l'Académie Royale des Sciences d'Outre Mer (ARSOM), pp. 684-715. 